\title{
The Japanese Suffix -Ppoi as a Modal
}

\author{
Fukumi Higashihira \\ Lecturer, Department of Civil Engineering \\ The University of Tokyo \\ Japan
}

\begin{abstract}
The Japanese suffix - ppoi makes an adjective and adds the meaning of 'seems like...' or 'has the appearance of...' to the original sentence, similar to the English -ish. -Ppoi follows nouns, verb stems and adjective stems. Recently, many people have started using -ppoi in their colloquial language, indicating speaker's degree of certainty and not merely just to indicate uncertainty as we have seen over the past. Traditionally, -ppoi, as in X-ppoi, functions only as a derivational suffix altering the meaning of the preceding word X. For newer usage of -ppoi, it is attached to the end of the sentence expressing speaker's attitude, uncertainty, etc., much like the other modals, sentence-final-soo 'I hear,' yoo, rashii, mitai 'seem', etc. This describes the expanded uses of -ppoi in current Japanese with the Google search for its ability to search for the current speech patterns of Japanese.
\end{abstract}

Keywords: Japanese, Suffix, Modal, Modality

\section{Introduction}

Recently, Japanese language has been going through considerable changes, in part due to technological innovations and information dissemination. It is said that Kojien (6th edition) added 10,000 new words in $2008^{1}$. The use of new words, rampant on television and the internet, in young people's magazines and in daily conversation, are often criticized. The present study examines the use of the suffix -ppoi '-ish', '-like'. -Ppoi turns the word to which it is attaches in to an $i$-adjective. According to Makino and Tsutsui (2001:340), -ppoi is "a suffix that indicates s.o. / s.t. has some distinctive characteristic or an attribute identified by a noun, an adjective, or a verb to which the suffix is attached." See examples (1a) - (1d). ${ }^{2}$

(1)

a. noun + ppoi: kodomo-ppoi 'childish'

b. $i$-adjective stem + ppoi: yasu-ppoi 'cheapish'

c. na-adjective stem + ppoi: aware-ppoi 'pitful'

d. verb masu + ppoi: wasure-ppoi 'easy to forget, forgetful'

Recently, -ppoi has been used in colloquial written language as a modal expressing the speaker's judgment. An example of -ppoi in its new usage is shown in (2) below, taken from a novel Golden Slumbers - A Memory by Kotaro Isaka (2007:242). This usage has expanded in recent years to mean 'seems like.' However, these expanded meanings, such as asondeiru-ppoi 'it seems like be playing'. also include the judgment that something seems like 'playing' as opposed to, for example, 'work.'

(2) Rinka-chan datte, sugee kansha shiteta ppoi shi.

'It seems like Rink also really appreciated you'.

In its traditional usage, -ppoi cannot follow the finite form of a verb. Iwasaki (2012) mentioned the part kokuhakusuru ppoi ndayo should be kokuhaku suru soo da (or rashii) yo 'I heard that (he) would, 'soo da (or rashii) expressing hearsay. Since -ppoi in sentence (2) expresses the meaning 'seem,' it can be substituted for by mitai. Note that -ppoi in such usage does not indicate a "distinctive characteristic or an attribute identified by a noun, an adjective, or a verb to which the suffix is attached." Another example of the contemporary use of -ppoi is found in a comic book title "Ppoi!" (Ish!), written by Takako Yamazaki. There is also a television drama with the same title. This use of -ppoi is particularly interesting because it appears without anything preceding it.

\footnotetext{
${ }^{1}$ Iwanami Shoten URL: http://www.iwanami.co.jp/kojien/

${ }^{2}$ Makino and Tsutsui (2001:338)

136
} 
The purpose of this study is to analyze the emergent use of -ppoi as a modal that comes at the end of the sentence and help understand contemporary Japanese conversation better.

\section{Literature review}

\subsection{Dictionary definitions}

According to Kojien, one of the most authoritative dictionaries in Japan, -ppoi means 'have characteristic of X' or 'tend to'. - Ppoi is a suffix attached to a noun, a verb, or an adjective, which turns the whole phrase into an adjective. When - poi is suffixed to a word, the first consonant 'p' becomes a geminate. Meikyo Kokugo dictionary (2010), offers three meanings of -ppoi. In the first case, it can be attached to a noun and express phrases like 'somewhat like X' (e.g. otoko-ppoi 'manly, masculine') or 'has a strong characteristic of X' (e.g., hokori-ppoi 'dusty', iro-ppoi 'sexy'). Secondly it can also be attached to a verb stem and express phrases like "there is a tendency" or "it is likely" (e.g. aki-ppoi 'get tired of something easily', hore-ppoi 'fall in love easily,' wasureppoi 'forget easily, forgetful.' Finally, it can also be found attached to an adjective stem and indicate that the characteristic is evident (e.g. ara-ppoi 'rough, rude', yasu-ppoi 'cheap', aware-ppoi 'plaintive, mournful').

According to Makino and Tsutsui (2001), -ppoi follows a noun and the stem of an $i$-adjective, a na-adjective, and a verb. They mentioned that "The nouns, adjectives, and verbs that can take the suffix -ppoi are not unlimited, but quite productive, especially when it is connected with a noun" (2008:343). They observed that -ppoi can be replaced either by the modals such as yasui, rashii, yoo and fuu 'like', depending on the preceding word. Yasui is not a true modal but means 'easy to do'.

\subsection{The meanings of -ppoi}

The dictionary definitions discussed above are helpful for understanding the conventional meaning of -ppoi. This research, however, is based on the new definitions given by Kojima (2003), Ohara (2010), Odani (2000, 2005) and Iwasaki (2011).

According to Kojima (2003), "When -ppoi is attached to a noun X, it fundamentally means "somehow it feels/seems like it is X'". Kojima's research says that 'X-ppoi' meant 'there is much X' or 'has a strong X-like element' in the Edo era. Since then, the meaning of -ppoi has changed to 'looks like X as a whole', and, finally it took on the meaning that 'there is almost X'. Ohara (2010) furthered Kojima's opinion and explained that "When -ppoi is attached to a word or phrase $\mathrm{X}$, it expresses that "it has more nature or elements of X".

Odani (2000) defines the meanings of X-ppoi. First, if X contains more than its standard value, it can be described as X-ppoi. For example, Shiro-ppoi is not exactly snow-white but similar to white. Secondly, Odani says that ppoi means 'having many characteristics of X.' For example, if a person has many childlike characteristics, we describe him/her as kodomo-ppoi 'childish, childlike' Lastly, Odani explains that -ppoi also has the meaning that contains the probability of decision making, "It has a great possibility of being categorized as X". (e.g. tanteejimusho-ppoi 'It has a great possibility of it being the detective firm.') Odani claims that -ppoi attached to verbs is categorized under this type (e.g. dekiteruppoi 'It seems that (that's how) it's made', owatteruppoi 'It seems that it's done').

Odani (2005) offers a broad interpretation of those meanings to 'many contents of the judgment possibility'. According to Odani, -ppoi like yoo 'it resembles, it looks like', rashii 'it seems', and mitaina 'it seems' has been established as a modal. Odani points out that a meaning of the suffix -ppoi is 'inference', and the speaker uses ppoi and other modals properly in order to convey his/her intention. Iwasaki (2011:76) states that in the example "Okako-san nadowa hone-ppokutehakidasareru 'The sailors are spewed up because they have the mettle' (Sanba Shikitei 1813), the Chinese character 多 'many/much' is used for -ppo(i), and that the basic meaning of -ppoi is 'there is a lot of...' from the historical viewpoint. Therefore, adding-ppoi to the nouns emphasize the original noun.

In the sentence: "X waY-ppoi. (X seems like Y.)", Iwasaki (2011) says that 'X =Y' is classified. -Ppoi can be classified into four categories according to what it expresses: (a) a characteristic, (b) an action, (c) an attribute, and (d) the speaker's inference. Iwasaki says that the fourth usage is a new meaning of -ppoi, and it began to be used at the end of the Showa era(1980s'). Iwasaki also says that -ppoi expresses the meaning of "inference based on evidence," as do rashii and yoo. This is the same as the third meaning described by Odani (2005). 
According to the studies above, -ppoi is used when the speaker is guessing, and it is interchangeable with rashii and yoo. Sunagawa, one of the authors of the Meikyo Kokugo dictionary, says that the meaning of -ppoi as currently used in dictionaries differs from the usage in Mondaina Nihongo (2008), which is one of the most popular books of its kind. She discusses two recent usages of -ppoi. One is to appear following the predicate of a sentence, as shown in (3).

(3) Sore ijoo wa nomanai hoo ga ii desu yo ppoi koto o iwareta.

'I was told something like I shouldn't drink anymore.'

Another type of-ppoi is found attached to loanword nouns and proper nouns; e.g. adaruto-ppoi 'be like an adult movie', ayu-ppoi 'be like Japanese singer Ms. Ayumi Hamasaki'. Such usage differs from the conventional one such as onna-ppoi 'feminine' and otoko-ppoi 'masculine'. These new -ppoi uses are interchangeable with yoo 'seem, resemble, look like,' rashii 'seem', mitai 'it seems', or kusai 'it resembles'. According to Sunagawa (2010), -ppoi has become a useful suffix which can be used freely. However, the new usage gives the impression that the suffix is a slang used by young people, and conveys a sense of exclusiveness, as an expression accepted only among friends.

\subsection{Previous research on -ppoi expressing uncertainty and hedging}

Kekidze (2003) says that X-ppoi is used when an object contains many elements of X, but that the element is not the largest constituent. She also says that -ppoi decreases the strength of $\mathrm{X}$ and she calls this effect yawarage 'softening'. A sentence is softened when a speaker avoids a strong assertive expression and instead chooses a nonassertive expression. In addition, about Kekidze discusses Murata's (1994:119) Bokashi Hyoogen 'hedging expression' Murata says that it is a type of expression that will allow the speakers to avoid limiting to press their decision, or standing out when making a statement. "Hedging expression" based on Lakoff's (1972) "hedges." Lakoff (1972:195) defines hedges as "words whose meaning implicitly involves fuzziness," and "words whose job it is to make things fuzzier or less fuzzy" Kekidze interprets-ppoi as a hedging expression because -ppoi is the way of speaking which avoids the assertion.

\subsection{Previous research on epistemic modality}

What is modality and its classifications will be explained in this section. According to Palmer (1986:16), "Modality in language is, then, concerned with subjective characteristics of an utterance, and it could even be further argued that subjectivity is an essential criterion for modality. Modality could, that is to say, be defined as the grammaticalization of speakers' (subjective) attitudes and opinions". Nyuts (2006:2) says that "modality comprises of three basic semantic dimensions: dynamic, deontic and epistemic." Dynamic modals are "traditionally characterized as an ascription of capacity to the subject-participant of the clause" (Nyuts 2006:3)In Japanese, dynamic modalities include nakerebanaranai 'have to, must',beki 'ought to', (se) zaruoenai 'must'. Deontic modal "is traditionally defined in terms of permission and obligation (Nyuts 2006:4; Parmer 1986: 9697)". In Japanese, deontic modalities include (suru/shita) hoogaii 'it would be better' and temoii 'it is all right...'. Epistemic modality "concerns the degree of speaker commitment to the information conveyed." (Iwasaki 2002:275). Japanese epistemic modals include stem-soo 'it looks', finite form-soo 'I hear', yoo 'it resembles, it looks like', rashii 'it seems', mitai 'it seems', hazu 'be supposed/expected to' and nichigainai'(guessing with confidence)'.

Makino and Tsutsui (2001) state that -ppoi can be replaced either by the modals such as yasui 'easy to do', rashii 'it seems', yoo 'it resembles, it looks like' and fuuno 'like' depending on the former word. Odani (2005) claims that -ppoi is used like yoo 'resemble, look like', rashii 'seem', and mitai 'it seems'. Tomita (2009) observes that the modality of supposition only lists soona 'it looks'. Kojima (2003), Ohara (2010) and Iwasaki (2011) analyzed the historical changes of -ppoi, and compared it with that of rashii 'seem'. Newer meanings of -ppoi include most of the meanings of the epistemic modalities.

Nitta (2009a, 2009b) lists three major sentence forms that can be used with epistemic modality expressions. The first one is 'the consequence of the hypothetical conditional sentence' (2009a:140). This sentence indicates that a modal appears in the result clause of the "if...,then..." sentence, and this includes epistemic modalities that are opinions based on evidence, for example, daroo 'probably', kamoshirenai 'may/might be', nichigainai 'must be', and $h a z u$ 'be supposed to'. These modalities express the assertion or denial or the possibility, impossibility or contingency as seen in (4) below. 
(4) Moshi ashita, takusan yuki ga futtara, gakko wa yasumi ni naru ni chigai nai. ${ }^{3}$

'If it snows much tomorrow, our school will be closed.'

In the above example, the speaker uses the modal nichigainai (inference with confidence) that predicts something that is not certain. The second one is 'the dependent clause as content of thought sentence' with the epistemic modality of evidential meaning. In such sentences, a modal appears in the embedded clause, followed by ...to omou 'I think/suppose/guess that...'. See example (5) below.

(5) Tanaka ga iinchoo ni naru daroo to omou. ${ }^{4}$

'I think Tanaka will probably be a representative.'

Note that we cannot use the evidential modality of the epistemic modality in the embedded clause of "...to omou."

(5)' *Tanaka ga iinchoo ni naru mitai da to omou. ${ }^{5}$

Tanaka ga iinchoo ni naru 'Tanaka will be the representative' is a sentence stating a fact which does not involve anyone's opinion or leave the possibility that the speaker is guessing but that he is drawing a conclusion based on some objective evidence. This cannot be stated as a thought certainly, so it cannot be used in an embedded clause of "...to omou". The third one is 'the sentence with an evaluative modifier'. In such sentences, a modal appears at the end of the sentence. They often contain adverbs or adverbial phrases expressing the speaker's evaluation of the event, such as ureshiikotoni 'thankfully, I am happy to say', saiwai 'fortunately', zannennakotoni 'regrettably', and ainiku 'unfortunately'.

(6) Ureshii koto ni, yuujin tachi ga tanjoobi ni purezento o kureru soo da. ${ }^{6}$

'Fortunately, I hear that my friends will give me the gift in my birthday'.

A sentence that follows an adverb of evaluation needs to be based on a fact or some kind of proof. Here if verbs, $i$-adjectives, $n a$-adjectives or nouns are examined to see if they can precede soo. Verbs and adjectives are followed by stem+soo 'look, seem'. Nouns cannot be used with stem+soo, and they would have to be attached to yoo or -ppoi to express the meaning 'seem, look.'

Nitta (2009a, 2009b) classifies the epistemic modality into five types, (a) jijitsu 'description', (b) dantee 'judgment', (c) suiryoo 'inference', (d) gaizen-see 'probability', (e) shooko-see 'evidential', according to their meanings. He further categorized these into three different types of sentences: kateijoken no kiketsu 'consequence of the hypothetical condition', shikoo-naiyoo 'content of thought' and hyooka no zentei 'evaluative modifier' and he tests weather epistemic modals can or cannot be attached to the end of these sentences. The five types of epistemic modality and the sentence patterns are shown in Table 1.

Table 1: Five types of epistemic modality and the sentence patterns (Nitta2009a:142)

\begin{tabular}{|c|c|c|c|}
\hline & $\begin{array}{l}\text { Consequence of the } \\
\text { hypothetical condition }\end{array}$ & Content of thought & Evaluative modifier \\
\hline (a).description & $\times$ & $x$ & $\circ$ \\
\hline (b).judgement & $\circ$ & $\circ$ & $\begin{array}{l}\times \\
\text { (with exceptions) }\end{array}$ \\
\hline (c).inference & $\circ$ & $\circ$ & $\begin{array}{l}\times \\
\text { (with exceptions) }\end{array}$ \\
\hline (d).probability & $\circ$ & $\begin{array}{l}\text { (except hazu) } \\
\text { (ext }\end{array}$ & $\begin{array}{l}\times \\
\text { (with exceptions) }\end{array}$ \\
\hline (e).evidential & $\begin{array}{l}\times \\
\text { (except soo) }\end{array}$ & $\begin{array}{l}\times \\
(\text { exceptsoo) }\end{array}$ & ० \\
\hline
\end{tabular}

According to Table 1 above, a sentence categorized in description simply states a fact and does not include a modality marker. Judgments sentence can be formed when there are progressive decisions. The modal that expresses inference is daroo. Modals expressing probability include kamoshirenai, nichiainai and hazu da.

\footnotetext{
${ }^{3}$ Nitta’s example(2009:140)

${ }^{4}$ Nitta's example(2009a:141)

${ }^{5}$ Nitta's example (2009a:141)

${ }^{6}$ Nitta's example (2009a:142)
} 
These modals help the speaker expresses the probability, possibility or inevitability of the matter to occur, although evidence is not required. Evidential modals are yoo, rashii, stem + soo and finite form + soo. These can only be used when there is some type of evidence. See examples (7a) - (7e).
a. description
Boku wa kinoo tokoya ni itta.
'I went to the barber yesterday.'
b. judgment
Kitto asu wa ame ni naru.
'Probably, it will be rain tomorrow.'
c. inference
Ame wa mada futte iru daroo.
'It is probably still raining.'
d. probability
Tanaka-san wa kuru kamo shirenai.
'Mr/Ms. Tanaka may come.'
e. evidential
Kono meron wa takai rashii.
'They say that this melon is expensive.'

Nitta (2009a) examined the similarities between (7a) and (7e), and between (7b), (7c) and (7d). The modals of (7a) and (7e) cannot appear in the consequence of assumption or the content of thought, however, only soo occurs in both sentences. The exception of evaluation sentence are $(7 \mathrm{~b}),(7 \mathrm{c})$, and $(7 \mathrm{~d})$, because with zannen-nagara 'unfortunately' all of the modals can occur. Nitta (2009a) also categorized the forms that precede epistemic modalities. These are connected to verbs and adjectives of non-past and past tenses, as well as modalities which add the speaker's judgment or probability to the sentence. The forms that precede the epistemic modality can be categorized as in Table2.

Table 2: The forms that precede epistemic modality expressions(Nitta2009a:136)

\begin{tabular}{|c|c|c|c|c|}
\hline & Verb & Adjective & na-Adjective & Noun \\
\hline Daroo & \multirow{9}{*}{$\begin{array}{l}\text { Non-past tense/ } \\
\text { Past tense }\end{array}$} & \multirow{9}{*}{$\begin{array}{l}\text { Non-past tense/ } \\
\text { Past tense }\end{array}$} & \multirow[t]{5}{*}{ Stem/Past tense } & \multirow[t]{5}{*}{$\mathrm{N} / \mathrm{N}+$ datta } \\
\hline kamoshirenai & & & & \\
\hline nichigainai & & & & \\
\hline mitai da & & & & \\
\hline Rashii & & & & \\
\hline$\varnothing$ & & & \multirow{2}{*}{$\begin{array}{l}\text { Non-past tense/ } \\
\text { Past tense }\end{array}$} & \multirow[t]{2}{*}{$\mathrm{N}+d a / \mathrm{N}+d a t t a$} \\
\hline soo da 'I hear' & & & & \\
\hline $\mathrm{Hazu}$ & & & \multirow{2}{*}{$\begin{array}{l}\text { Stem }+n a / \\
\text { Past tense }\end{array}$} & \multirow[t]{2}{*}{$\mathrm{N}+\mathrm{no} / \mathrm{N}+$ datta } \\
\hline yoo da & & & & \\
\hline soo da 'seem' & Stem & Stem & Stem & $x$ \\
\hline
\end{tabular}

Quoted from Nitta (2009a) directly however, the tenses were added by the author. $\varnothing$ means there is no modal. The modals except for stem + soo $d a$ 'seem' can all appear with the finite form; i.e. non-past and past, affirmative and negative; e.g. ikudaroo, ikanaidaroo, ittadaroo, ikanakattadaroo. Only soo follows the stem of verbs, $i$ adjectives, $n a$-adjectives and nouns. The only exception is the copula $d a$, which has its own peculiar pattern. All epistemic modalities can be classified in this table. If the suffix-ppoi has the meaning of a modal, it must conform to these tables. We will try to find a similar modality with -ppoi.

\section{Hypothesis and Analysis}

In previous studies, the meaning of -ppoi was regarded as the same as that of the modalities of inference like rashii, yoo, mitai or soo 'seem'. However, the nuance of using -ppoi and these modals are different. In this study, the meaning of -ppoi is the primary focus, rather than comparing its meanings to other modals. According to Makino and Tsutsui (2000), rashii is "an auxiliary adjective which indicates that the preceding sentence is the 
speaker's conjecture based on what he has heard, read or seen" and means "seem, look like, apparently and I heard". Yoo da is "an auxiliary na-type adjective which expresses the likelihood of s.t. / s.o. to s.t. / s.o." and means "look like; look as if; be like; appear and seem". They mentioned that "the colloquial version of yoo da is mitai $d a$, which is also a na-type adjective. The uses of mitai da are exactly the same as those for yoo da". Soo da can be of two types. One soo da is "an auxiliary which indicates that the information expressed by the preceding is what the speaker heard" and means "I hear that , I heard that , People say that. ." Another soo da is "an auxiliary adjective which indicates that information expressed by the preceding sentence is the speaker's conjecture concerning an event in the future or the present state of someone or something, based on what the speaker sees or feels" and means "look, look like, appear, seem, feel like."

According to Maynard (2009), rashii expresses a 'non-self-committing speculation'. She explains that "A structure using $i$-type auxiliary adjective rashii 'it seems' expresses speculation based on information, primarily obtained from sources other than self' (e.g., gakuseerasihifun'iki 'the atmosphere like a student'). Yoo has two meanings, "Firstly, it is used to mean in English 'it seems' to express that something is approximately $X$ although it is not quite $X$. ... Secondly, it is used to mean in English 'it appears (to me)' or 'it seems (to me)' when the speaker expresses a personal judgments to the likelihood of a state or event (e.g., omocha no yoonakagi 'a keylike a toy')". She saysmitai is a colloquial expression and that it is similar to the meaning of yoo 'it seems' (e.g. amegafuttekitayooda ${ }^{7}$ 'It seems that it began to rain'). She calls stem-soo an 'eye-witness conjecture', which can 'add the meaning of 'looks (as if)' and 'appears as if'. When using soo, the speaker conveys that as far as he or she is concerned, the information typically accompanying what one conjectures is immediately available and is directly observed (e.g., sonokeekioishisoo da naa 'That cake looks delicious ${ }^{8}$ ')."

Nitta (2009a) analyzes modals by using each one in three types of sentences in order to determine which one is most appropriate. Here, the use of -ppoi will be examined by attaching it to the end of sentences and by comparing it to other modalities. Since the scope of this study is limited to understanding when and how the new usage of -ppoi evolved and its underlying purpose, the present study does not include a statistical survey, nor does it discuss the frequency of -ppoi.

\subsection{Hypothesis}

This study is based on the hypothesis that -ppoi can be attached to the end of a sentence expressing the speaker's attitude, uncertainty, etc. In order to test this hypothesis, the meanings of-ppoi shall be categorized in a manner that is similar to how Nitta (2009a) categorized the meanings of modalities. Moreover, whether -ppoi can appear in sentences expressing the consequence of a hypothetical condition, content of thought, and subjective evaluation, shall be evaluated by collecting data through Google search engine.

\section{2 -Ppoi in the conclusion of hypothetical condition}

Nitta (2009a) states that evidential modality cannot come at the end of a sentence, unlike the modality of prediction and probability, using the conclusion of hypothetical condition sentences.

(8) Moshi, Satoo ga konokoto o shittara, bikkuri suru \{daroo / kamo shirenai / ni chigai nai / hazu da \}. 'If Sato found out about it, he/she \{ will probably / may / must / should \} be surprised.' 9

(8)' Moshi, Satoo ga konokoto o shittara, bikkuri \{ *suru yoo da / *suru mitai da / *suru rashii / *suru soo da / shisoo da $\}^{10}$

'If Sato found out about it, he/she $\{*$ it seems that $\mathrm{s} /$ he will $/ *$ it seems that $\mathrm{s} /$ he will/* it seems that $\mathrm{s} /$ he will / *I hear that's/he will / it seems that s/he will \} be surprised.'

Only the evidential modality soo can appear at the end of the consequence sentence of the hypothetical conditional sentence. This is because soo can be used without any evidence. -Ppoi can be used at the end of the consequence of the hypothetical conditional sentence. Observe (9) and (10).

\section{(9) Posuto kaado toka ni nattara ii-ppoi. ${ }^{11}$}

\footnotetext{
${ }^{7}$ Maynard (2009:233)

${ }^{8}$ Maynard (2009:228)

${ }^{9}$ Nitta's example (2009a:139)

${ }^{10}$ Nitta's example (2009a:139)
} 
'It would be nice if it became a postcard.'

(10) Ima wa isogashiku te taihenda kedo, nigatsu ni haittara donichi moshikashitara yasumi-ppoi. ${ }^{12}$

'Right now, I am busy, but I may have Saturday and Sunday off in February.'

There were approximately 50, 900 hits of the phrase 'tara ii-ppoi' when I Googled (April 1, 2013). According to Nitta (2009a, 2009b), the adverbial phrase moshikashitara 'possibly' is used frequently when a sentence ends with the modal kamoshirenai 'might be, maybe.' The meaning of moshikashitara is almost the same as that of moshikasuruto/shite and hyottosuruto/shite/shitara.

The combination of -ppoi and all these phrases were found in Google Search. We can say, therefore, that -ppoi can be used in the conclusion of hypothetical condition. Moreover, yasumi-ppoi omitted 'ninaru' because the ninaru part of the sentence is understood instinctively or culturally.

\section{3 -Ppoi in a content of thought}

In this section we examine whether-ppoi can be substituted at the end of the embedded clause of "I think...". As shown in (5)in the sentence "Tanaka gaiinchoooninarudaroo to omou. "I think Tanaka will be a representative"".

(11) Tanaka ga iinchoo ni \{narudaroo /narukamoshirenai /narunichigainai /narudaroo\} to omou. ${ }^{13}$

'I think \{ Tanaka will probably / Tanaka may / Tanaka must / I hear Tanaka will \} be a representative.'

(11)'Tanaka ga iinchoo ni \{ $\{$ naruyoo da / *narumitai da / *narurashii / *narisooda $\}$ toomou. ${ }^{14}$

'I think $\{*$ I heard that Tanaka will be /*Tanaka seems to be /*Tanaka must be /*Tanaka will probably be are presentative.'

Sentence (11) is the example of the collision of meanings. All the modalities used in (11) mean 'I hear that...' which indicate the information was obtained by an outside source, whereas 'to omou' indicates that it is the speaker's idea and interpretation. Therefore, in sentences like (11), evidential modality is not allowed. There were approximately $11,900,000$ hits on narisoo da to omou. Therefore, it can be inferred that the phrases narisooda and to omou 'I think...' can be properly used in a sentence. Examples of -ppoi were found to be used with to omou 'I think...'. They are provided in (12) and (13).

(12) Doyoubi wa musume-san mo iru node nantoka naru-ppoi to omou. ${ }^{15}$

'Their daughter is home on Saturday (so even if something happens) it will be OK-ish, I think.'

(13) C-8 ga nanda kanda de kekkoo sonogo no kiso ni naru-ppoi to omou kyoo konogoro. ${ }^{16}$

'Nowadays, I think that C-8 will eventually become the basis-ish after everything settles down.

\section{4 -Ppoi as a subjective evaluation}

Evaluation adverbs or phrases, start off the clause by offering a subjective evaluation of it e.g. koounnimo 'fortunately', zannennagara 'unfortunately', etc.

Modality is used with evaluation adverbs or phrases adverb which show that the adverbs include ureshiikotoni 'happy to say', saiwai 'fortunately', zannennnakotoni 'unhappy to say' and ainiku 'unfortunately'. Nitta (2009) states that the only time one can use the words of the subjective evaluation is when the evidential modality exists in a sentence like (14).

(14) Ureshii kotoni, yuujin ga purezento o \{kureta/kureru kamo shirenai /kureru daroo /kureru hazu da\}.

'I am happy to say that my friends \{gave me / may give me / will probably give me / is supposed to give me\} a gift.'

Sentence (15) indicates that - ppoi can be used in a sentence with Subjective evidence.

(15) Ureshii koto ni, atode noboru koto ni naru sakamichi o kakeagaru muki ni kaze ga fuiteru-ppoi. ${ }^{17}$

\footnotetext{
11 “Homepage” http://www.geocities.jp/hibiyamanken/@geoboard/195.html

12 “Kiramekumainichini” http://www.dclog.jp/en/6072170/439977525

${ }^{13}$ Nitta's example (2009:141)

${ }^{14}$ Nitta's example (2009:141)

15 "2 channel" http://uni.2ch.net/test/read.cgi/atopi/1282204021/1100

16 "2 channel” http://mimizun.com/log/2ch/arc/1025183997

17 "Kaettekita (?) jpgr's page: Kako-choo" http://www.ok.au-hikari.ne.jp/jpgr/diary/diary1211.html
} 
'Luckily, by the time we must run up that hill, the wind will be blowing from behind.'

To summarize the findings in 3.2 to 3.4, -ppoi can be attached at the end of a sentence expressing the conclusion of hypothetical condition, a content of thought, and a subjective evaluation. The only modality that can be used similarly is stem+soda as shown in Table 1.

\subsection{Forms that precede -ppoi}

We now examine the forms of the words to which -ppoi can be attached. The forms examined are; verb (non-past tense (16), past tense (17)), imperative (18), $i$-adjective (19), $n a$-adjective (20), copula (21), pronouns (22), particle (23), adverb (24), gerund form (25), conjunction (N/A) and interjection (N/A). It can be combined with many different forms of words.

(16) Ima wa Ameichi to iu-ppoi. ${ }^{18}$

'(It seems that) today, they call it Ameichi.'

(17) Otto, omoiyari de itta-ppoidesu. ${ }^{19}$

'It seems that my husband said it out of his kindness.'

(18) Sono go, ressha ga ugoite inai koto o wasurete ite Kawaguchi-eki e iku. Eki wa shimatte ori dare mo inai...soko ni chuugokujin dansei ga yatte kite chuugokugo de densha wa nai, mukoo e ike-ppoi koto wo ittekita. $^{20}$

"After that, forgetting that the trains are not moving,I went to Kawaguchi station. The station was closed and no one was there. Then, a Chinese man said something like "The train is not moving, go over there-ish" in Chinese.'

(19) Atsui node burogu no fun'iki o kaetai naa to omotte suzushii-ppoi noni shite mimashita. ${ }^{21}$

'Because it was hot, I wanted to change the atmosphere of my blog and changed to the design which seems to be cool'.

(20) Boku, genki desu-ppoi. ${ }^{22}$

'I seem to be pretty well. / I think, I'm ok,man'

(21) Tabun dakedo kore-ppoi! Arigatoo! ${ }^{23}$

'This seems to be the book./ I think, the book is mine. Thankssooooooooo much!'

(22) Atte yokatta ne-ppoi. ${ }^{24}$

'It seems great that you found it. / Like, it's great you found it.'

(23) Chinamini saikin hajimatta saabisu rasiku, ten' in ni yotte wa narete nai no mo shibashiba-ppoi. ${ }^{25}$

'FYI, I have heard the service was so new and some staff donot even know much about it.'

I heard that it would seem that the service that has recently been introduced depends on the server.

Consequently, the examples of -ppoi can be attached. Therefore, my hypothesis was confirmed.

\section{Findings}

If -ppoi can be used in the end of all three types of sentences, then it means that it can be used to guess something. It can also be used when the speaker has some kind of evidence and he/she has a strong belief. According to Nitta (2009a), stem+soo and -ppoi have similar characteristics to Table 3.

\footnotetext{
18 “Twitter” https://twitter.com/9nf/status/275287367840055296

19 "HatsugenKomachi" http://komachi.yomiuri.co.jp/t/2013/0110/565616.html

20 "SekaiNozokimiChindocyu" http://sekaichindouchu.web.fc2.com/diarychina.html

21 "Midori moyou"http://cream417.blog.fc2.com/blog-entry-10.html

${ }^{22}$ Blog“'Genki-kun no Cable Nikki”http://genkijanaiyo.blog101.fc2.com/blog-entry-43.html

23 "Nikonikodaihyakka (tentative)"http://dic.nicovideo.jp/b/a/\%E3\%81\%93\%E3\%82\%8C $\%$ E3\%81\%AA\%E3\%82\%93\%E3\%81\%A6\%E6\%9B\%B2 $\%$ E3\%81\%A0\%E3\%81\%A3\%E3\%81\%91\%3F/721-

24 “Twitter"https://twitter.com/torikinchan/status/247104627026313216

${ }^{25}$ Blog“'Dizzy Alice’s Ribald Karma” http://ziocities.net/blog/2008/08/post-14.html
} 
Maynard (2008) characterizes stem+soo as 'eye-witness conjecture'. This is an epistemic modal that expresses the speaker's impression and opinion and is attached to the stem of a verb and adjective. It adds meaning such as 'looks (as if)' and 'appears as if', to the conjunctive form of the verb (e.g., He may go.), $i$-adjective stem (It looks big.) and $n a$-adjective stem (He looks fine.). Tomita (2008:121) states that a noun cannot be used preceding soo, and that soo is replaced by -ppoi, for example, gakusei-ppoi 'student-like'. However, the former word of -ppoi and soo are different. If we only focus on the mannerism of the words preceding -ppoi, stem+soo is closer to the meaning of -ppoi in this usage. Therefore, the meanings implied with sentences using -ppoi are closer in form of prior word to soo. Nitta (2009a:140) explains that a sentence using soo includes an observation by the speaker, and the sentence with soo is based on information attained from someone else. -Ppoi is not restricted by the source of the information. This is because, originally, -ppoi was used as a suffix to emphasize elements and characteristics of the noun which it is attached to (Iwasaki 2011:84). Therefore, we can say that -ppoi is used to emphasize the word preceding that or the sentence itself. Also, -ppoi fits under all three sentences and since it can follow various different types of words with restrictions, the usage of -ppoi cannot be covered only by stem + soo.

-ppoi can be more freely used than other epistemic modalities. Below is each epistemic modality and examples, which show the use of-ppoi that can be replaced with others. This study exhibits a collection of the sentences in which we can see examples of Nitta's theory of epistemic modality (2009a) with evaluation adverbs and phrases. For example,

[moshikashitara...kamosirenai]

(24) Setsubun ga moshikashitara yasumi ni naruppoinde, Saijoo Inari ni ikoo kana to omou n da kedo, donna junbi o shite ikeba ii no daroo $\mathrm{ka}^{26}$

'Setsubun might be cancelled, so I was thinking of going to Saijoo Inari and wondering how I should prepare for it'.

[kitto...nichigainai]

(25) Kyaa, Nakama, nakama (naritaku nai ka.) tteka, kitto wazato ppoi desu yo ne. Kamatte hoshii mitai na. ${ }^{27}$ 'Oh,we're the same! But it might look like I'm doing it on purpose to get attention.' [toozen...hazu da]

(26) Edajima wa kanbu-kouhosei dakara toozen (Enei wo) yatte(i)ru ppoi. ${ }^{28}$

'Edajima is an executive trainee,so he must have a long-distance swim.'

[tabun...daroo]

(27) Kaimono no ato wa HY-kun ga keibajoo de hanabi o mi ni ikoo to iu koto nanode tabun iku ppoi desu. ${ }^{29}$

'After shopping, Mr. HY is going to see fireworks at the racetrack so I'm probably going.'

As far as we can see in the examples above, there are a few common relevancies, but each of the forms varies. Therefore, when -ppoi follows verbs, nouns, adjectives, adverbs and conjunctions, as well as sentences, it means that it has changed the combination of these phrases. Initially, I believed that -ppoi included various meanings of the modalities, but my findings suggest that this misunderstanding was due to the fact that-ppoi is an expression that can be used to capture the five senses.

Table 3: Five types of epistemic modality and the sentence patterns appear with -ppoi

\begin{tabular}{|l|c|c|c|}
\hline & Consequence of the hypothetical condition & Content of thought & Evaluative modifier \\
\hline (a).description & $\times$ & $\times$ & $\circ$ \\
\hline (b).judgement & $\circ$ & $\circ$ & $\begin{array}{c}\times \\
\text { (with exceptions) }\end{array}$ \\
\hline (c).inference & 0 & $\circ$ & $\begin{array}{c}\times \\
\text { (with exceptions) }\end{array}$ \\
\hline (d).probability & $\circ$ & $\begin{array}{c}\circ \\
\text { (except hazu) }\end{array}$ & $\begin{array}{c}\times \\
\text { (with exceptions) }\end{array}$ \\
\hline
\end{tabular}

\footnotetext{
${ }^{26}$ Blog "Daroburo...sohsitedensetsu e..." http://rifflove.blog36.fc2.com/blog-entry-687.html

${ }^{27}$ Blog”Mamaninaru tame ni @ Ai” http://chamicha.a-thera.jp/article/305063.html

28 “2 Channnel”http://www.logsoku.com/r/jsdf/1083989077/

${ }^{29}$ Blog "Bondo-baka"http://bakabondo.blog15.fc2.com/?mode=m\&no=23\&m2=res 


\begin{tabular}{|l|c|c|c|}
\hline (e).evidential & $\begin{array}{c}\times \\
(\text { except } s o o)\end{array}$ & $\begin{array}{c}\times \\
(\text { except soo })\end{array}$ & $\circ$ \\
\hline (f).-ppoi & $\circ$ & $\circ$ & $\circ$ \\
\hline
\end{tabular}

Table 4: The forms that precede epistemic modality expressions with -ppoi

\begin{tabular}{|c|c|c|c|c|}
\hline & Verb & Adjective & na-Adjective & Noun \\
\hline Daroo & \multirow{9}{*}{$\begin{array}{c}\text { Non-past } \\
\text { tense/Past tense }\end{array}$} & \multirow{9}{*}{$\begin{array}{c}\text { Non-past } \\
\text { tense/Past tense }\end{array}$} & \multirow{5}{*}{ Stem/Past tense } & \multirow{5}{*}{$\mathrm{N} / \mathrm{N}+$ datta } \\
\hline kamoshirenai & & & & \\
\hline nichigainai & & & & \\
\hline mitai da & & & & \\
\hline Rashii & & & & \\
\hline$\varnothing$ & & & Non-past tense & \multirow{2}{*}{$\mathrm{N}+d a / \mathrm{N}+$ datta } \\
\hline soo da 'I hear' & & & /Past tense & \\
\hline Hazu & & & Stem $+n a /$ & \multirow{2}{*}{$\mathrm{N}+\mathrm{no} / \mathrm{N}+$ datta } \\
\hline yoo da & & & Past tense & \\
\hline soo da 'seem' & Stem & Stem & Stem & $x$ \\
\hline -ppoi & $\begin{array}{c}\text { Non-past tense/ } \\
\text { Past tense/ } \\
\text { Imperative } \\
\text { Form }\end{array}$ & $\begin{array}{c}\text { Stem / } \\
\text { Non-past } \\
\text { tense/Past tense }\end{array}$ & $\begin{array}{c}\text { Stem/ } \\
\text { Non-past } \\
\text { tense/Past tense }\end{array}$ & $\frac{\mathrm{N} /}{\mathrm{N}+\operatorname{data} / \mathrm{N}+\text { particle }}$ \\
\hline
\end{tabular}

Nevertheless, we need to focus on the situations where $n a$-adjectives are able to precede both-ppoi and soona. Both shizukasoona 'quiet-like morning' and shizuka-ppoi 'quiet-like morning' comes from his or her impression, but there has to be some kind of difference between the two. For example,

(28) Shizuka de wa nai kedo, ima genzai wa shizuka-ppoi asa.. ${ }^{30}$

'It is not quiet, but it is a quiet-ish morning right now.'

In sentence (28), the speaker does not really think that the current morning is quiet, but -ppoi indicated that it is similar to or has the partial characteristic of a quiet morning. Soo meaning 'seem' cannot be used when the speaker has already experienced the situation and -ppoi can be. It seems that shizuka-ppoi expresses both 'uncertainty' and 'hedging'. When not knowing the context, the reader/listener probably would not know if -ppoi was used in the sense to express the similarity to the preceding word or in the sense of modalities and feels its meaning of 'uncertainty' and 'hedging'. It may be that the speaker is trying to make his statement vaguer. Moreover, by saying it that way, the statement sounds softer. However, I suspect that we may need to look more closely at the general meaning of both -ppoi and stem+soona in order to understand the notion.

You would say oishisoona keeki 'delicious-looking cake' before eating it, but you never say oishiippoi keeki. There were no hits when we searched "oishiippoi keeki." When comparing -soo and -ppoi, oishisoona seems more suitable since the evaluation that it "seems delicious" is based solely on the visual observation, but stem+soo is not necessarily based on visual information alone. You can hear something and say "omoshiro-soo," smell something and say "oishi-soo," etc. On the other hand, the following example was found.

(29) Tabe owatta ato, oishii ppoi kanji ga suru. ${ }^{31}$

'After eating, this gives me a delicious-ish feeling.'

Sentence (29) is similar to shizukappoi asa. The speaker of (29) uses oishiippoi 'delicious-ish' after tasting the soba noodles. The fact that one uses oishisoona before tasting and oishiippoi after tasting might give us some clue about their difference in meanings, because it can be inferred that the speaker wanted to emphasize the fact that there was an element that tasted delicious rather than just that he considered that element to be delicious. Oishiiyoo da can be used without tasting something or hearing about the taste from someone. Therefore, depending upon which modal is used, the meaning of the word changes significantly.

\section{Conclusion}

30 “Osamu no Ukiyo Nikki” http://osamu64.at.webry.info/200812/article_10.html

31 “Tabelog Tokyo" http://tabelog.com/tokyo/A1313/A131305/13008091/dtlrvwlst/4010166/ 
Soo cannot be used with nouns, but - ppoi can be used. Since nouns are not conjugated, they can be replaced by a non-conjugating phrase and it can be verified by finding a finite form or a command form of a word before -ppoi. A better understanding of the meaning and usage of-ppoi as a modal helps to understand one aspect of Japanese daily conversation. In addition, it is useful for Japanese language teachers to learn the use of -ppoi and other modals in order to teach learners authentic contemporary usage.

It is important for teachers to emphasize meaningful language use for real communicative purposes. A common complaint among learners of Japanese is that the language in textbooks is very different from the contemporary spoken language among native speakers. Understanding the usage of -ppoi will help bridge that gap by emphasizing samples from authentic, real-life sources, and bringing them into the classroom. We hope that the results of the present study will benefit both teachers and students.

\section{Acknowledgements}

The present paper is based on the author's master thesis at Columbia University, concluded in 2013. She would like to express gratitude to wonderful teachers and friends. In particular, she wants to thank Professor Mutsuko Endo Hudson and Professor Seiichi Makino for teaching memorable lessons and sharing valuable thoughts. Thank you very much.

\section{References}

Inoue, Fumio. 1994. Hoogengaku no shin-chiheisen. 3-14. Meiji Shoin, Tokyo, Japan.

Isaka, Kotaro. 2007. Golden Slumbers, Shinchosha, Tokyo, Japan

Iwasaki, Mariko. 2011. On the Historical Change of "poi" through Meanings and Usages: Journal of Humanities and Social Sciences. 31, 83-96. Published Dissertation. Okayama University, Okayama, Japan. Retrieved from http://ousar.lib.okayama-u.ac.jp/metadata/44437

Iwasaki, Shoichi. 2002. Japanese. Ch. 13. Pragmatics and grammar, pp. 94-109.John Benjamins Publishing, VA, USA.

Kekidze Tatiana. 2003. Semantic Analysis of "poi". Teaching Japanese as a Foreign LanguageVol.11. The Society for Teaching Japanese as a Foreign Language, Tokyo, Japan.

Kitahara, Yasuo. 2005. Zokudan Mondaina Nihongo.Taishukan-Shoten, Tokyo, Japan

Kojima, Satoko. 2003. Setsubi-go "-poi” no henka

Maynard, Senko K. 2009. An introduction to Japanese grammar and communication strategies. The Japan Times. Tokyo, Japan.

Makino, Seiichi, and Michio Tsutsui. 2000. A Dictionary of Basic Japanese Grammar. The Japan Times, Tokyo, Japan.

Makino, Seiichi, and Michio Tsutsui. 2001. A Dictionary of Intermediate Japanese Grammar. The Japan Times, Tokyo, Japan.

Murata. Mihoko. 1994. Bokashi hyoogen no shin-hookoo. No.59 (7). Kokubun-gakukaishaku to kanshoo.pp.119126. Shibun-doo, Tokyo, Japan.

Lakoff, George. 1972. "Hedges: A study in meaning criteria and the logic of fuzzy concepts", Papers from the Eighth Regional Meeting of the Chicago Linguistic Society, 183-228. Reprinted in Journal of Philosophical Logic, 1973, 2: 4, 458-508, and in D. Hockney et al. (eds.). Contemporary research in philosophical logic and linguistic semantics. Dodrecht: Fortis, 221-271.

Nitta, Yoshio. 2009a. Modern Japanese Grammar Vol.4. Nohongo Kijutsu Bunpo Kenkyukai. Tokyo, Japan.

Nitta, Yoshio. 2009b. Japanese Modality and its surrounding. Hitsuji-Shobo. Tokyo, Japan.

Nuyts, Jan. 2006. Modality: Overview and linguistic issues. In: W. Frawley (ed.), The expression of modality, 126. Berlin: Mouton.

Ohara, Masako. 2010.On the Suffix "poi”. Faculty of Law and Literature, Department of Language and Culture. Shimane University, Shimane, Japan. Retrieved from http://sir.lib.shimane-u.ac.jp/metadb/u p/bull.pl?id=7081

Odani, Masanori. 2000.The mechanism of categorizing of a suffix. . Japan Language Testing Association, Tokyo Japan. Retrieved fromhttp://www.i.hosei.ac.jp/odani/poi_2000.pdf

Odani, Masanori. 2005. Setsubiji Poi no Modality ka. The Pragmatics Society of Japan, Tokyo, Japan.

Palmer, F. R. 1986. Mood and modality. Cambridge: Cambridge University Press. 
Shibatani, Masayoshi.1990. The Languages of Japan. Ch. 11.6. Pragmatics, pp. 357-392.Cambridge University Press, UK.

Tomita, Hideo. 2009. Essentials of Japanese Grammar for Teachers. Kuroshio Shuppan. Tokyo, Japan.

Yamazaki, Takako. 1991. Ppoi!. Hakusen-sha. Tokyo, Japan.

\section{URL}

Retrieved 10 31, 2018, from Midori Moyoo: http://cream417.blog.fc2.com/blog-entry-10.html

Retrieved 10 31, 2018, from Genki-kun no Cable Nikki: http://genkijanaiyo.blog101.fc2.com/blog-entry-43.html

Retrieved 10 31, 2018, from Alice's Ribald Karma: http://ziocities.net/blog/2008/08/post-14.html

Retrieved 10 31, 2018, from Daroburo... sohsite densetsu e...: http://rifflove.blog36.fc2.com/blog-entry-687.html

Retrieved 10 31, 2018, from Mama ni naru tame ni@Ai: http://chamicha.a-thera.jp/article/305063.html

Retrieved 10 31, 2018, from Mama ni naru tame ni@Ai: http://chamicha.a-thera.jp/article/305063.html

Retrieved 10 31, 2018, from Bondo-baka: http://bakabondo.blog15.fc2.com/?mode=m\&no=23\&m2=res

Retrieved 10 31, 2018, from Osamu no Ukiyo Nikki: http:/osamu64.at.webry.info/200812/article_10.html

2 Channel. Retrieved 10 31, 2018, from http://uni.2ch.net/test/read.cgi/atopi/1282204021/1100

2 Channel. Retrieved 10 31, 2018, from http://mimizun.com/log/2ch/arc/1025183997/

2 Channel. Retrieved 4 1, 2013, from http://www.logsoku.com/r/jsdf/1083989077/

Hatsugen Komachi. Retrieved 10 31, 2018, from http://komachi.yomiuri.co.jp/t/2013/0110/565616.htm

Homepages. Retrieved 10 31, 2018, from http:/www.geocities.jp/hibiyamanken/@geoboard/195.html

Kaette kita (?) ipgr's page. Retrieved 10 31, 2018, from Koko-choo: http://www.ok.auhikari.ne.jp/jpgr/diary/diary1211.html

Nikoniko Daihyakka. Retrieved 10 31, 2018, from

http://dic.nicovideo.jp/b/a/\%E3\%81\%93\%E3\%82\%8C\%E3\%81\%AA\%E3\%82\%93\%E3\%81\%A6\%E6\%9B\%B2 \%E3\%81\%A0\%E3\%81\%A3\%E3\%81\%91\%3F/721-Sekai Nozokimi Chindoochuu. Retrieved 1031 , 2018 , from

http://sekaichindouchu.web.fc2.com/diarychina.html

Tabelog Tokyo. Retrieved 10 31, 2018, from

http://tabelog.com/tokyo/A1313/A131305/13008091/dtlrvwlst/4010166/

Twitter. Retrieved 10 31, 2018, from https://twitter.com/9nf/status/275287367840055296

Twitter. Retrieved 10 31, 2018, from https://twitter.com/torikinchan/status/247104627026313216 